\title{
Pioglitazone use in patients with diabetes and risk of bladder cancer: a systematic review and meta- analysis
}

This article was published in the following Dove Press journal: Cancer Management and Research

\author{
Huaqing Yan \\ Haiyun Xie \\ Yufan Ying \\ Jiangfeng $\mathrm{Li}$ \\ Xiao Wang \\ Xin Xu \\ Xiangyi Zheng \\ Department of Urology, First \\ Affiliated Hospital, Zhejiang \\ University, Hangzhou, Zhejiang \\ Province, China
}

Correspondence: Xiangyi Zheng Department of Urology, First Affiliated Hospital, School of Medicine, Zhejiang University, Hangzhou 310003, China

Email zheng_xy@zju.edu.cn

\begin{abstract}
Pioglitazone has been reported to increase the risk of bladder cancer but the conclusions of published clinical studies are confusing. We conducted a systematic review and metaanalysis of all eligible randomized controlled trial (RCT) studies and observational studies, in order to identify a more precise relationship between pioglitazone and risk of bladder cancer. We searched for publications up to January 24, 2018, in PubMed, EMBASE, Scopus, Web of Science, Cochrane register, and Chinese National Knowledge Infrastructure databases, and the references of the retrieved articles and relevant reviews were also checked. Relative risk and $95 \%$ confidence interval (CI) were used to assess this correlation. A dose-related meta-analysis was performed as well. Data on RCT studies showed a null association between pioglitazone and bladder cancer. The pooled RR estimates of the 12 included studies illustrated that pioglitazone is associated with a $14 \%$ increased risk of bladder cancer (95\% CI 1.03-1.26). No evidence of publication bias was detected. In the dose effect analysis, patients who used a higher dose of pioglitazone had an increased risk of bladder cancer. In conclusion, this meta-analysis indicated that pioglitazone is associated with an increased risk of bladder cancer. Further research should be conducted to confirm our findings and reveal the potential biological mechanisms.
\end{abstract}

Keywords: thiazolidinedione, bladder tumor, epidemiology, dose effect, risk factor

\section{Introduction}

Bladder cancer has become a common cancer worldwide and ranks as the ninth most frequently diagnosed cancer. In 2012, approximately 430000 new cases of bladder cancer were diagnosed. ${ }^{1}$ Cigarette smoking, specific exposure to arylamine, and chronic schistosoma infection are the most associated factors with increased risk for bladder cancer. ${ }^{2}$ In recent years, diabetes mellitus (DM) has been reported to increase the risk of bladder cancer. ${ }^{3,4}$ Meanwhile, pioglitazone, an antidiabetic agent of the thiazolidinedione (TZD) class, which is broadly used for glycemic control in patients with type 2 diabetes mellitus (T2DM), has been reported to increase the risk of bladder cancer as well. At first, the risk was reported in male rats, ${ }^{5}$ then, a series of clinical studies was performed to identify this relationship. However, the conclusions of published observational clinical studies remain confusing. ${ }^{6-25}$ This may result from problems associated with study design, limited sample size, and a lack of attention to potential biases. In 2016, one randomized controlled trial (RCT) (PROactive) ended its 10-year observational follow-up drawing a conclusion that the imbalance in bladder cancer cases observed during the double-blind period did not persist, and there was no overall increase in malignancies. ${ }^{26}$ But only one RCT result could not end the argument. In 2017, another 
RCT (TOSCA.IT) also reported null association between pioglitazone and bladder cancer, but the number of bladder cancer cases in this RCT was only 16, which may not be convincing. ${ }^{27}$ A large cohort study including 193099 people by Lewis et al also reported no statistically significant increased risk of bladder cancer associated with pioglitazone use. ${ }^{8}$ However, the updated US Food and Drug Administration review in 2016 concluded that use of T2DM medicine pioglitazone may be linked to an increased risk of bladder cancer, ${ }^{28}$ which conflicted with the newly updated RCT results by Erdmann et al, ${ }^{26}$ Vaccaro et al, ${ }^{27}$ and cohort study by Lewis et al. ${ }^{8}$ In the most recently updated meta-analysis conducted by Davidson and Pan, ${ }^{29}$ they suggested the resurrection of the use of pioglitazone, but failed to perform sensitivity analysis and simply pooled observational studies together without excluding the duplicate population and low-quality studies (Table S1). ${ }^{16,17,20-22}$ In another recent meta-analysis by Filipova et al, ${ }^{30}$ they failed to give any details about quality assessment and simply pooled RCT and observational studies together without excluding the duplicate population and low-quality studies. They did not perform subgroup analysis either, though his result showed significant heterogeneity. Other meta-analyses are not convincing mainly because inadequate evidence acquisition, poor methodology, and lack of appropriate quality assessment. Consequently, despite a number of observational studies and previous reviews, ${ }^{29,31-33}$ whether pioglitazone increases the risk of bladder cancer or not still remains an enigma. We conducted a systematic review and meta-analysis of all eligible RCTs, cohort studies, and nested case-control studies about pioglitazone use in patients with diabetes and bladder cancer in order to identify a more precise and reliable relationship between pioglitazone and risk of bladder cancer. Furthermore, we also examined whether the association between them converts according to sensitivity analysis.

\section{Materials and methods Publication search}

This meta-analysis was performed according to the Preferred Reporting Items for Systematic Reviews and Meta-analyses (PRISMA) guidelines. ${ }^{34}$ We carried out a search in PubMed, EMBASE, Scopus, Web of Science, Cochrane register, and Chinese National Knowledge Infrastructure databases, covering all the eligible papers published up to January 24, 2018. The search strategy included terms for outcome (bladder neoplasm* or bladder cancer* or bladder tumor* or bladder tumour*) and exposure (pioglitazone* or TZD* or thiazolidinedione*). We carefully evaluated every potentially relevant publication by examining their titles and abstracts.
All the studies matching the inclusion criteria were retrieved. The references from retrieved articles and reviews were also thoroughly checked to identify any additional relevant studies. All analyses were based on previous published studies, thus no ethical approval and patient consent are required.

\section{Inclusion criteria}

Studies included in this meta-analysis had to meet all the following criteria: a) an RCT design or a cohort design or a nested case-control design; b) the population included in studies were patients with diabetes; $c$ ) one of the exposures of interest was pioglitazone; d) one of the outcomes of interest was incidence of bladder cancer and the result is recorded in a reliable database or using ICD codes of cancer; e) studies provided rate ratio, hazard ratio (HR) or standardized incidence ratio (SIR) with their 95\% confidence intervals (CIs), or sufficient data to calculate them; and $f$ ) they were of high quality according to the Newcastle-Ottawa scale (NOS) (more than 6$)^{35}$ or were assessed to have low risk of bias, using the recommended tool in the Cochrane Handbook for Systematic Reviews of Interventions. ${ }^{36}$ Research on mortality rates of bladder cancer was not included because it could be unpredictably confounded by survival-related factors. We also did not consider studies in which the population included healthy people because diabetes was also considered to increase the risk of bladder cancer. If multiple publications from the same study population were available, the most recent and detailed study was entitled to be included in this meta-analysis.

\section{Data extraction}

Two authors extracted data independently by using a predefined data collection form, with disagreements being resolved by consensus. For each study, the following characteristics were collected: first author's name, year of publication, the country in which the study was carried out, participant characteristics (age and sex), study design, study population, range for follow-up, number of events and non-event subjects exposed to pioglitazone and comparison, medication use in comparison group, estimate effects with their 95\% CIs and covariates adjusted for in the analysis. From each of the studies, we optionally excerpted the relative risk estimate that was adjusted for the greatest number of potential confounders. In dose effect analysis, we defined low dose as $\leq 8268 \mathrm{mg}$ or $\leq 10500 \mathrm{mg}$ or $\leq 14000 \mathrm{mg}$; moderate dose as 10501-28000 mg or 14001-40000 mg; high dose as $>28000 \mathrm{mg}$ or $>40000 \mathrm{mg}$.

Quality assessment of searched papers was also undertaken independently by two authors according to the NOS for 
observational studies, and Cochrane Tool Review Manager 5.3 for RCTs. The disagreements between authors were resolved by discussion and consensus.

\section{Statistical methods}

Studies that reported various measures of RR were included in this meta-analysis: rate ratio, HR, and SIR. In practice, these three measures of effect yield similar estimates of RR because the absolute risk of bladder cancer in patients with diabetes is low.

Overall RR estimates with their corresponding 95\% CIs were calculated with the DerSimonian and Laird ${ }^{37}$ random effects models, which consider both within-study and between-study variation. Heterogeneity among studies was measured by $\mathrm{Q}$ test and quantified by $\mathrm{I}^{2}$ with higher value indicating a greater degree of heterogeneity. Random effects model was chosen to analyze the data. ${ }^{38}$ Publication bias was assessed using Begg's test $\mathrm{t}^{39}$ (rank correlation method) and Egger's test (linear regression method). ${ }^{40} P<0.05$ was considered to be representative of a significant statistical publication bias. Dose effect analysis of pioglitazone was conducted if data were sufficient. Sensitivity analyses were also performed to assess the stability of obtained results with a single study deleted each time to manifest the influence of the individual dataset to the pooled RR. All of the statistical analyses were performed with STATA 14.0 (StataCorp LP, College Station, TX, USA), using two-sided $P$-values.

\section{Results}

\section{Literature search}

Figure 1 outlines our study selection process. Briefly, after removing duplicates, the search strategy generated 561 articles. Of these, the majority was excluded after the first screening based on abstracts or titles, mainly because they were reviews, basic research, case-control studies, or obviously not relevant to our analysis. After full-text review of 21 papers, 14 studies were excluded for the following reasons: low NOS quality score , $^{1718,20,41,42}$ outcomes were not bladder cancer; ${ }^{43,44}$ duplicate population; ${ }^{16,22}$ used rosiglitazone as reference group; ${ }^{45}$ used non-DM people as reference group; ${ }^{46,47}$ without reference; ${ }^{11}$ obviously abnormal data (details of exclusion criteria in Table S1). ${ }^{23}$ We also identified five publications through checking reference lists of retrieved studies and reviews. Thus, a total of 12 cohort studies or nested case-control studies, ${ }^{7-10,12-15,19,23-25}$ which met the inclusion criteria, were included in the meta-analysis. Two RCT studies ${ }^{26,27}$ were also identified in this process and were systematically reviewed.

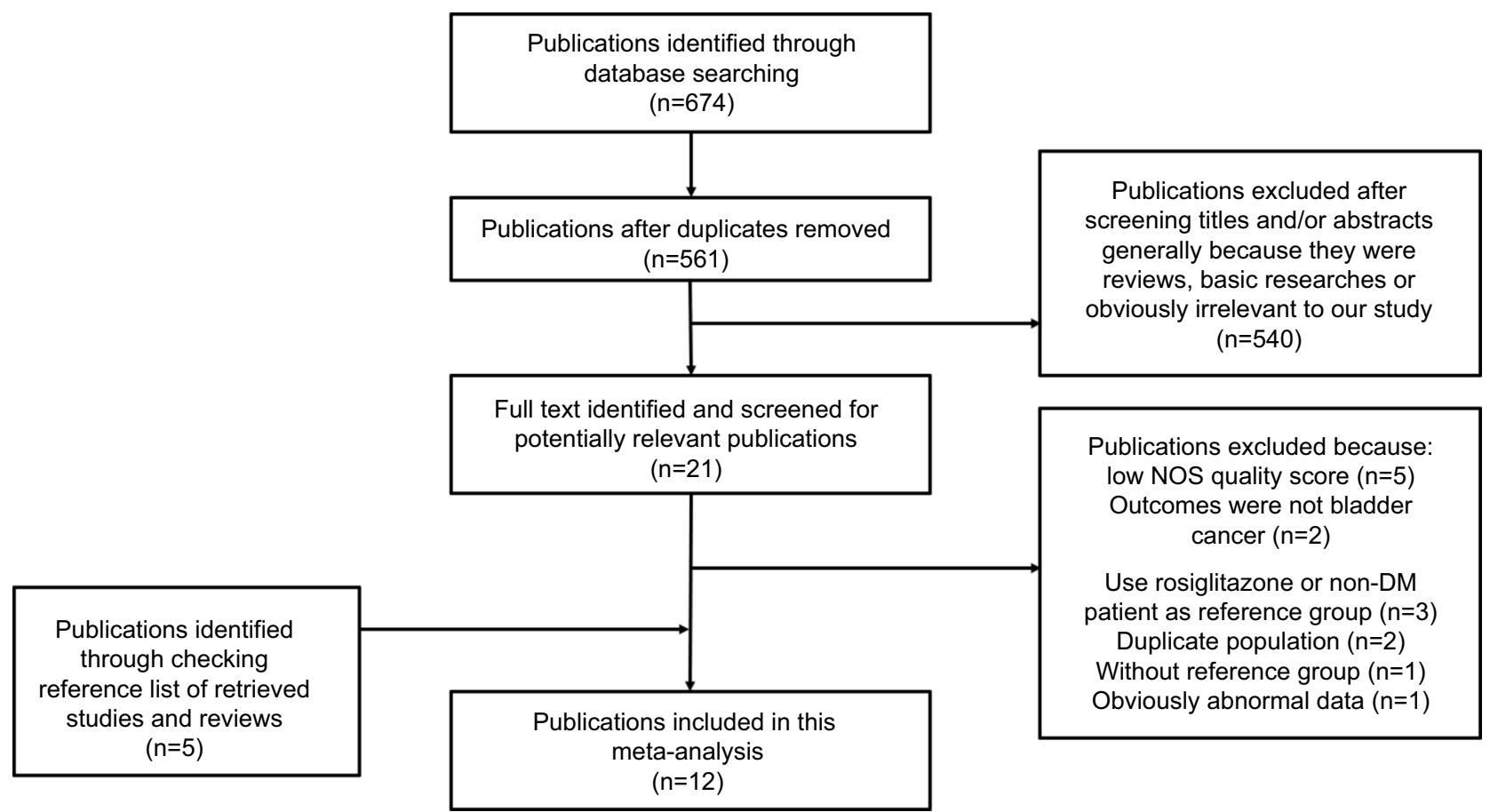

Figure I Flowchart of study assessment and selection.

Abbreviations: NOS, Newcastle-Ottawa scale; DM, diabetes mellitus. 


\section{Data obtained from RCTs}

Two RCT studies, PROactive ${ }^{26}$ and TOSCA.IT, ${ }^{27}$ which reported bladder cancer cases in patients with diabetes, were eligible for this study. As it is meaningless to perform a metaanalysis for two studies, we systematically reviewed them. Characteristics including population, interventions, years of follow-up, and number of cases are shown in Table S2. Risk of bias assessment of the studies is demonstrated in Figure S1.

The PROactive study was performed in patients with T2DM who were aged 35-75 years. Among a total of 5238 patients who were enrolled in the PROactive study, 2605 patients were randomized to the pioglitazone group and 27 bladder cancer cases were identified finally after doubleblind period +10 -year observational follow-up. Meanwhile, 26 cases were reported in the placebo group which consisted of 2633 T2DM patients who took placebo. The authors found no significant association between pioglitazone and bladder cancer with RR and 95\% CI 1.05 (0.61-1.79). The other study, TOSCA.IT, was a multicenter prospective, randomized, open label, blinded end point designed. The authors reported eight cases in metformin + pioglitazone $(n=1535)$ and metformin + sulfonylurea group $(n=1493)$. Similar to the PROactive study, no significant relationship was detected. Both studies were assessed to have a low risk of bias (Figure S1).

\section{Data obtained from observational studies} Study characteristics

The characteristics of the 12 observational studies are presented in Table 1. Of these, eight t, $^{6,10,12,14,15,19,25}$ were cohort studies and four ${ }^{7,9,13,24}$ were nested case-control studies. The studies were conducted in the following regions: Europe $(\mathrm{n}=5),{ }^{10,13-15,19}$ Asia $(\mathrm{n}=4),{ }^{6,7,9,24}$ and USA $(\mathrm{n}=3) .{ }^{8,12,25}$ The study population in 12 studies consisted of both sexes. All included studies were published between 2012 and 2018. The cohort ranged in size from $878^{24}$ to 1.01 million. ${ }^{19}$ Medication use in comparison group was either "never used any TZD"13,24 or "never used pioglitazone" ${ }^{-10,12,14,15,19}$ or "use of sulfonylureas". ${ }^{25}$ Adjustments were made for potential confounders of more than two factors in all studies.

\section{Pioglitazone use and risk of bladder cancer}

The overall RR with its 95\% CI showed a statistically slight but significant association between pioglitazone use and risk of bladder cancer (Figure 2, RR 1.14, 95\% CI 1.03-1.26). There is no significant heterogeneity among these studies with $\mathrm{Q}=17.86, P=0.085$, and $\mathrm{I}^{2}=38.4 \%$.
We also performed dose effect analysis of pioglitazone (Table 2). We defined low dose as $\leq 8268 \mathrm{mg}$ or $\leq 10500$ $\mathrm{mg}$ or $\leq 14000 \mathrm{mg}$; moderate dose as 10501-28000 mg or $14001-40000 \mathrm{mg}$; high dose as $>28000 \mathrm{mg}$ or $>40000 \mathrm{mg}$. Although there were not statistically significant results, the risk of bladder cancer showed a rising trend when the dose of pioglitazone increased (low dose, RR 1.12, 95\% CI 0.95-1.33; moderate dose, RR 1.20, 95\% CI 0.99-1.46; high dose, RR 1.29, 95\% CI 0.75-2.22).

\section{Sensitivity analysis}

Sensitivity analyses of the pooled RRs were performed to test the stability of the pooled results. All of the integrated RRs were once again calculated by means of the random effects model. When omitting each study in the meta-analysis, the pooled RRs (Table S3) always remained stable.

\section{Publication bias}

There was no evidence indicating significant publication bias either with the Begg's test $(P=1.0)$ or with the Egger's test (Figure 3, $P=0.90$ ).

\section{Discussion}

The finding of this meta-analysis of 12 studies indicates that pioglitazone is associated with a $14 \%$ increased risk of bladder cancer (95\% CI 1.04-1.26). Quantified Q test and $\mathrm{I}^{2}$ test were carried out to assess the extent of heterogeneity among the included studies. No statistically significant heterogeneity was found among the included studies $\left(\mathrm{I}^{2}=38.4 \%, P=0.085\right)$. Our conclusion was convincing because a fixed model showed a similar result (RR 1.05, 95\% CI 1.01-1.10) and our heterogeneity was not significant. In sensitivity analysis we found that heterogeneity largely decreased $\left(\mathrm{I}^{2}=0, P=0.591\right)$ when excluding Levin et al's ${ }^{19}$ study. This result may be due to the difference in methodology of Levin et al's paper. Unlike other cohort studies, Levin used a multi-population pooled cohort to assess the risk of bladder cancer and use of pioglitazone in patients with type 2 diabetes. This might be the origin of the heterogeneity. Although the result of two RCT studies providing high-level evidence showed a null association between pioglitazone and bladder cancer, it is still not convincing because a total of only 35 bladder cancer cases were reported in the intervention group. During our search process, another high-quality RCT study assessing risk of bladder cancer and pioglitazone in patients without diabetes was identified. ${ }^{47}$ Similar to two other RCTs, 12 bladder cancer cases in the pioglitazone group were reported and 


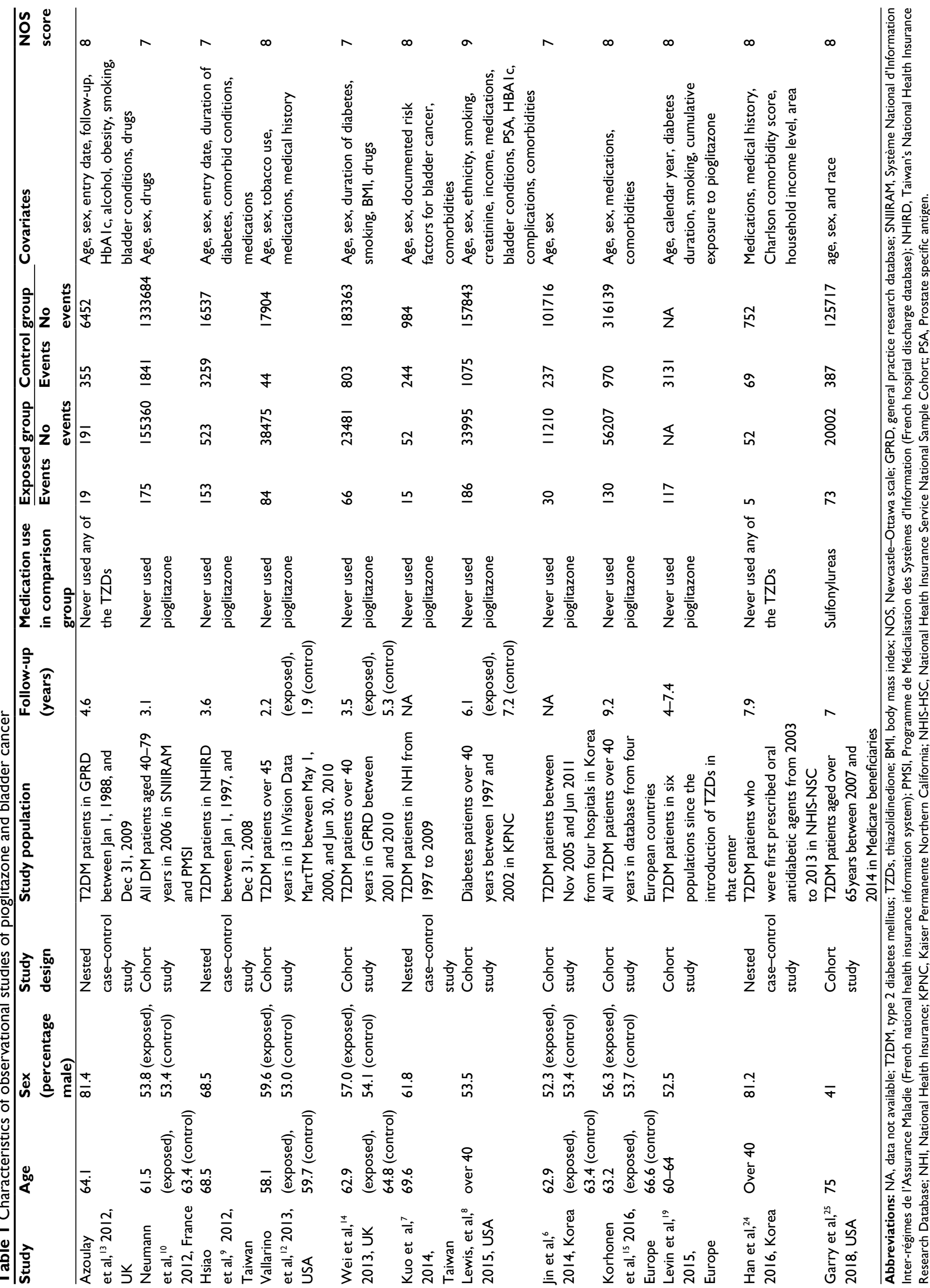




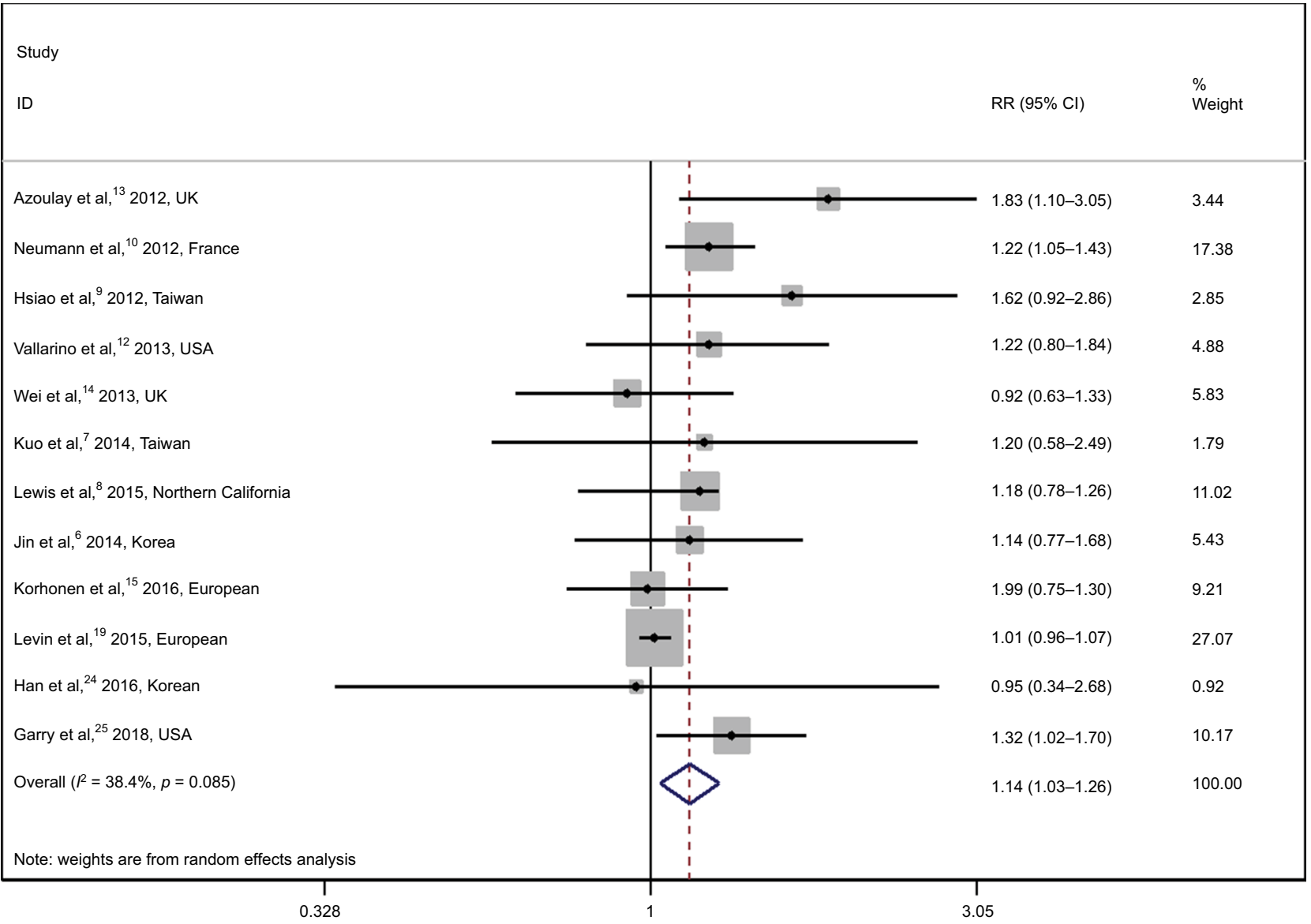

Figure 2 Relative risks for the association between pioglitazone use and risk of bladder cancer.

Notes: Diamonds represent study-specific relative risks (RRs) or summary relative risks with $95 \%$ confidence intervals (Cls). Horizontal lines represent $95 \%$ Cls. Test for heterogeneity among studies: $P=0.085, P^{2}=38.4 \%$.

Table 2 Dose effect analysis of relative risks for the association between pioglitazone and bladder cancer

\begin{tabular}{lllll}
\hline Dose used & RR $(\mathbf{9 5} \% \mathbf{C I})$ & \multicolumn{3}{c}{ Heterogeneity test } \\
\cline { 3 - 5 } & & $\mathbf{Q}$ & $\mathbf{P}$ & $\boldsymbol{I}^{\mathbf{2}} \mathbf{( \% )}$ \\
\hline Low & $\mathrm{I} .12(0.95-1.33)$ & $\mathrm{I}$ & $0.9 \mathrm{I}$ & 0 \\
Moderate & $\mathrm{I} .20(0.99-1.46)$ & 2.5 & 0.47 & 0 \\
High & $1.29(0.75-2.22)$ & 9.4 & 0.02 & 67.9 \\
\hline
\end{tabular}

Notes: Low dose is defined $\leq 8268 \mathrm{mg}$ or $\leq 10500 \mathrm{mg}$ or $\leq 14000 \mathrm{mg}$; moderate dose is defined I050I-28000 mg or 1400I-40000 mg; high dose is defined $>28000 \mathrm{mg}$ or $>40000 \mathrm{mg}$.

Abbreviations: $\mathrm{RR}$, relative risk; $\mathrm{Cl}$, confidence interval.

no significant relationship was detected. In spite of its high quality, this study was excluded from the systematic review because the non-diabetic population did not fit our study goal.

One important molecular signaling pathway involved in carcinogenesis concerns of pioglitazone intake and risk of bladder cancer. Pioglitazone is a member of TZDs, which are agonists of PPAR $\gamma .^{48}$ The effects of PPAR $\gamma$ agonists on human bladder cell lines have continually demonstrated significantly decreased proliferation, increased differentiation and apoptosis, suggesting that PPAR $\gamma$ is involved in antitumor action. ${ }^{49-51}$ However, recent research reported by Yang et al indicates that higher expression of PPAR $\gamma$ or its activation by agonist TZD can promote bladder cancer cell migration and invasion, ${ }^{52}$ suggesting that different expression levels of PPAR $\gamma$ may induce different outcomes. In light of this point, pioglitazone, the PPAR $\gamma$ agonist, might cause higher expression of PPAR $\gamma$ which promotes the process of carcinogenesis. In the future, more basic experimental research should be conducted to further elucidate the possible molecular mechanism of pioglitazone intake and risk of bladder cancer.

Our results of dose effect support this molecular theory. Patients who used a higher dose of pioglitazone had an increased risk of bladder cancer, indicating that larger amounts of pioglitazone may cause higher expression of PPAR $\gamma$ which promotes the process of carcinogenesis.

Additionally, no evidence of significant publication bias was observed in the analyses either with the Begg's test or 


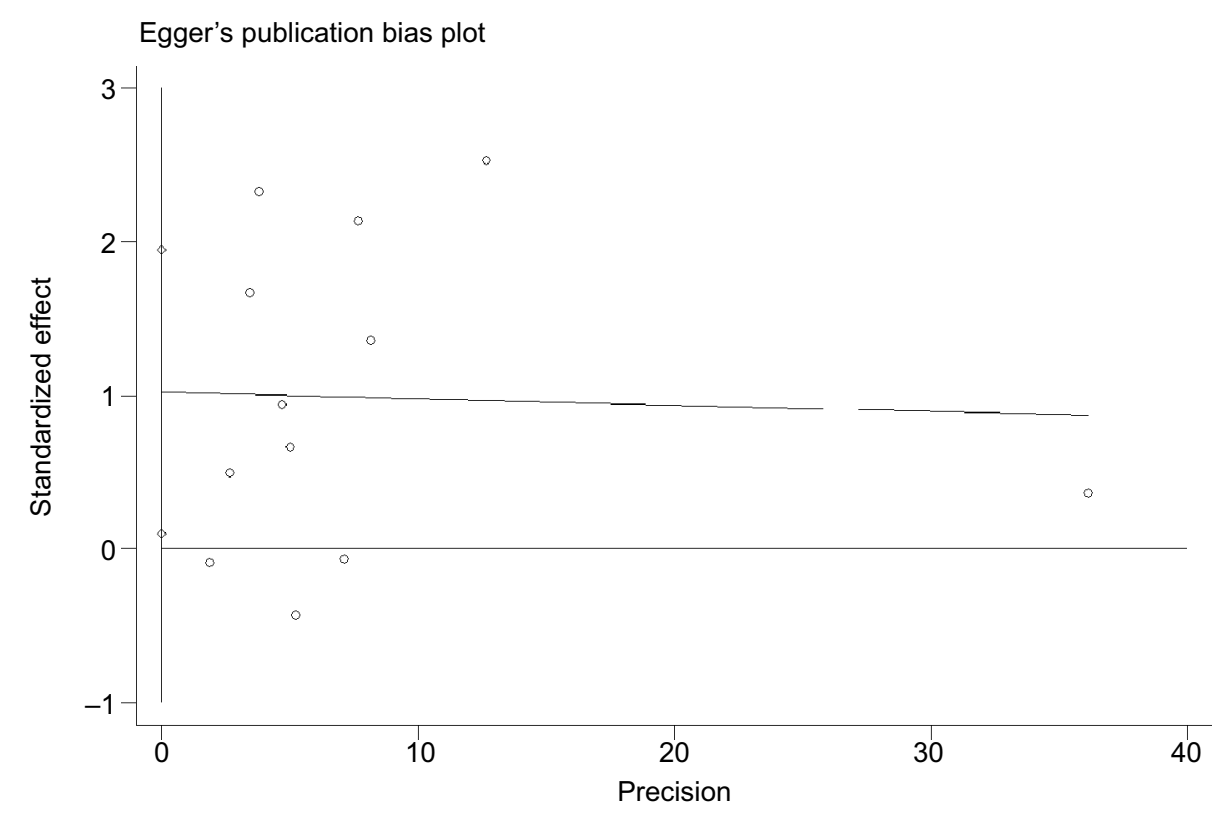

Figure 3 Egger's publication bias plot.

Notes: Egger's regression asymmetry test $(P=0.90)$. Standardized effect was defined as the odds ratio divided by its standard error. Precision was defined as the inverse of the standard error.

Egger's test. These results greatly improved the predictability and reliability of our meta-analysis.

Compared to other related meta-analyses, our metaanalysis evaluating the correlation between pioglitazone and risk of bladder cancer is more convincing because: a) a transparent and robust approach was taken to examine the evidence base, including adherence to PRISMA guidelines; b) we included the newest and the broadest studies, to the best of our knowledge, with rigid inclusion criteria restriction in which only RCTs and high-quality (NOS quality score $>6$ ) cohort studies or nested case-control studies were included. We did not include the other high-quality RCT by Kernan et $\mathrm{al}^{47}$ because the study population excluded patients with type 2 diabetes, which did not fit our aim. One RCT had another quality assessment method ${ }^{36}$ and was systematically reviewed rather than pooling with observational studies. A previous meta-analysis ${ }^{33}$ simply pooled results of RCTs and observational studies which makes the conclusions unconvincing. c) Patients' outcomes were only recorded in reliable databases or using ICD codes. This approach ensured methodological rigor. d) We did not include case-control studies to avoid latent high selection and recall bias; e) previous meta-analyses ${ }^{29,30}$ did not exclude studies with duplicate populations. ${ }^{9,16,22}$

Nevertheless, some limitations should be mentioned: a) we only pooled cohort studies and nested case-control studies without RCTs. Two RCTs, ${ }^{26,27}$ which provided convincing level 1 evidence, reported null association between pioglitazone use and bladder cancer, but there was only a total of 35 bladder cancer cases in the intervention group. More future RCT studies should be performed to provide more convincing evidence. b) Although no publication bias was found in our meta-analysis by either Egger's or Begg's test, the selection strategy of published studies and language limitation could bring about potential publication bias which may have affected our ultimate findings; c) the uncontrolled or unmeasured latent risk factors could have produced biases. We cannot rule out the possibility that remaining confounding factors could have affected the results. Recently, Lewis et $\mathrm{al}^{54}$ reported that proteinuria testing could potentially cause unmeasured confounding in studies of pioglitazone and bladder cancer but most of the studies included in this metaanalysis $^{6,7,9,10,12-14}$ did not adjust for proteinuria testing. d) Although our heterogeneity was not significant, the results of our meta-analysis should be interpreted with caution because heterogeneity of our study was not unapparent $(\mathrm{Q}=17.86$, $P=0.085$ and $\mathrm{I}^{2}=38.4 \%$ ).

In conclusion, this meta-analysis indicated that pioglitazone is associated with an increased risk of bladder cancer. Despite some study limitations, we still suggest that doctors should carefully assess the overall risks and benefits of pioglitazone. Further research should be conducted to confirm our findings and clarify the potential biological mechanisms. 


\section{Acknowledgments}

This work was supported by grants from the National Natural Science Foundation of China (Grant No. 81472375 and No. 81702500) and Zhejiang Province Medical Technology Project (2016KYA173).

\section{Disclosure}

The authors report no conflicts of interest in this work.

\section{References}

1. Antoni S, Ferlay J, Soerjomataram I, et al. Bladder cancer incidence and mortality: a global overview and recent trends. Eur Urol. 2017;71(1):96-108.

2. Murta-Nascimento C, Schmitz-Drager BJ, Zeegers MP, et al. Epidemiology of urinary bladder cancer: from tumor development to patient's death. World J Urol. 2007;25(3):285-295.

3. Xu X, Wu J, Mao Y, et al. Diabetes mellitus and risk of bladder cancer: a meta-analysis of cohort studies. PloS One. 2013;8(3):e58079.

4. McConkey DJ, Choi W, Ochoa A, Dinney CP. Intrinsic subtypes and bladder cancer metastasis. Asian J Urol. 2016;3(4):260-267.

5. Suzuki S, Arnold LL, Pennington KL, et al. Effects of pioglitazone, a peroxisome proliferator-activated receptor gamma agonist, on the urine and urothelium of the rat. Toxicol Sci. 2010;113(2):349-357.

6. Jin SM, Song SO, Jung $\mathrm{CH}$, et al. Risk of bladder cancer among patients with diabetes treated with a $15 \mathrm{mg}$ pioglitazone dose in Korea: a multi-center retrospective cohort study. J Korean Med Sci. 2014;29(2):238-242.

7. Kuo HW, Tiao MM, Ho SC, Yang CY. Pioglitazone use and the risk of bladder cancer. Kaohsiung J Med Sci. 2014;30(2):94-97.

8. Lewis JD, Habel LA, Quesenberry CP, et al. Pioglitazone use and risk of bladder cancer and other common cancers in persons with diabetes. JAMA. 2015;314(3):265-277.

9. Hsiao FY, Hsieh PH, Huang WF, Tsai YW, Gau CS. Risk of bladder cancer in diabetic patients treated with rosiglitazone or pioglitazone: a nested case-control study. Drug Saf. 2013;36(8):643-649.

10. Neumann A, Weill A, Ricordeau P, et al. Pioglitazone and risk of bladder cancer among diabetic patients in France: a population-based cohort study. Diabetologia. 2012;55(7):1953-1962.

11. Mackenzie TA, Zaha R, Smith J, Karagas MR, Morden NE. Diabetes pharmacotherapies and bladder cancer: a medicare epidemiologic study. Diabetes Ther. 2016;7(1):61-73.

12. Vallarino C, Perez A, Fusco G, et al. Comparing pioglitazone to insulin with respect to cancer, cardiovascular and bone fracture endpoints, using propensity score weights. Clin Drug Investig. 2013;33(9):621-631.

13. Azoulay L, Yin H, Filion KB, et al. The use of pioglitazone and the risk of bladder cancer in people with type 2 diabetes: nested case-control study. BMJ. 2012;344:e3645.

14. Wei L, MacDonald TM, Mackenzie IS. Pioglitazone and bladder cancer: a propensity score matched cohort study. Br J Clin Pharmacol. 2013;75(1):254-259.

15. Korhonen P, Heintjes EM, Williams R, et al. Pioglitazone use and risk of bladder cancer in patients with type 2 diabetes: retrospective cohort study using datasets from four European countries. BMJ. 2016;354:i3903.

16. Lee MY, Hsiao PJ, Yang YH, Lin KD, Shin SJ. The association of pioglitazone and urinary tract disease in type 2 diabetic Taiwanese: bladder cancer and chronic kidney disease. PloS One. 2014;9(1):e85479.

17. Balaji V, Seshiah V, Ashtalakshmi G, Ramanan SG, Janarthinakani M. A retrospective study on finding correlation of pioglitazone and incidences of bladder cancer in the Indian population. Indian J Endocrinol Metab. 2014;18(3):425-427.

18. Gupta S, Gupta K, Ravi R, et al. Pioglitazone and the risk of bladder cancer: an Indian retrospective cohort study. Indian J Endocrinol Metab. 2015;19(5):639-643.
19. Levin D, Bell S, Sund R, et al. Pioglitazone and bladder cancer risk: a multipopulation pooled, cumulative exposure analysis. Diabetologia. 2015;58(3):493-504.

20. Fujimoto K, Hamamoto Y, Honjo S, et al. Possible link of pioglitazone with bladder cancer in Japanese patients with type 2 diabetes. Diabetes Res Clin Pract. 2013;99(2):e21-23.

21. Song SO, Kim KJ, Lee BW, et al. The risk of bladder cancer in korean diabetic subjects treated with pioglitazone. Diabetes Metab J. 2012;36(5):371-378.

22. Tseng CH. Pioglitazone and bladder cancer: a population-based study of Taiwanese. Diabetes Care. 2012;35(2):278-280.

23. Tuccori M, Filion KB, Yin H, et al. Pioglitazone use and risk of bladder cancer: population based cohort study. BMJ. 2016;352:11541.

24. Han E, Jang SY, Kim G, et al. Rosiglitazone use and the risk of bladder cancer in patients with type 2 diabetes. Medicine (Baltimore). 2016;95(6):e2786.

25. Garry EM, Buse JB, Lund JL, Pate V, Sturmer T. Comparative safety of pioglitazone versus clinically meaningful treatment alternatives concerning the risk of bladder cancer in older US adults with type 2 diabetes. Diabetes Obes Metab. 2018;20(1):129-140.

26. Erdmann E, Harding S, Lam H, Perez A. Ten-year observational followup of PROactive: a randomized cardiovascular outcomes trial evaluating pioglitazone in type 2 diabetes. Diabetes Obes Metab. 2016;18(3): 266-273.

27. Vaccaro O, Masulli M, Nicolucci A, et al. Effects on the incidence of cardiovascular events of the addition of pioglitazone versus sulfonylureas in patients with type 2 diabetes inadequately controlled with metformin (TOSCA.IT): a randomised, multicentre trial. Lancet Diabetes Endocrinol. 2017;5(11):887-897.

28. fda.gov [homepage on the Internet]. FDA Drug Safety Communication: Updated FDA review concludes that use of type 2 diabetes medicine pioglitazone may be linked to an increased risk of bladder cancer. US Food and Drug Administration; 2016. Available from: https://www.fda. gov/Drugs/DrugSafety/ucm519616. Accessed May 2, 2018.

29. Davidson MB, Pan D. An updated meta-analysis of pioglitazone exposure and bladder cancer and comparison to the drug's effect on cardiovascular disease and non-alcoholic steatohepatitis. Diabetes Res Clin Pract. 2017;135:102-110.

30. Filipova E, Uzunova K, Kalinov K, Vekov T. Pioglitazone and the risk of bladder cancer: a meta-analysis. Diabetes Ther. 2017;8(4): 705-726.

31. Pai SA, Kshirsagar NA. Pioglitazone utilization, efficacy \& safety in Indian type 2 diabetic patients: a systematic review \& comparison with European Medicines Agency Assessment Report. Indian J Med Res. 2016;144(5):671-680.

32. Turner RM, Kwok CS, Chen-Turner C, et al. Thiazolidinediones and associated risk of bladder cancer: a systematic review and meta-analysis. Br J Clin Pharmacol. 2014;78(2):258-273.

33. He S, Tang YH, Zhao G, et al. Pioglitazone prescription increases risk of bladder cancer in patients with type 2 diabetes: an updated metaanalysis. Tumor Biol. 2014;35(3):2095-2102.

34. Moher D, Liberati A, Tetzlaff J, Altman DG; PRISMA Group. Preferred reporting items for systematic reviews and meta-analyses: the PRISMA statement. Ann Intern Med. 2009;151(4):264-269.

35. Ottawa Hospital Research Institute [homepage on the Internet]. Wells GA, Shea B, O'Connell DO, et al. The Newcastle-Ottawa Scale (NOS) for assessing the quality of nonrandomised studies in meta-analyses. Available from:http://www.ohri.ca/programs/clinical_epidemiology/ oxford.asp. Accessed May 2, 2018.

36. Higgins JP, Green S, editors. Cochrane Handbook for Systematic Reviews of Interventions Version 5.1.0 [updated March 2011]. The Cochrane Collaboration; 2011. Available from: http://handbook. cochrane.org. Accessed May 2, 2018.

37. DerSimonian R, Laird N. Meta-analysis in clinical trials. Control Clin Trials. 1986;7(3):177-188.

38. Zeng D, Lin DY. On random-effects meta-analysis. Biometrika. 2015;102(2):281-294. 
39. Begg CB, Mazumdar M. Operating characteristics of a rank correlation test for publication bias. Biometrics. 1994;50(4):1088-1101.

40. Egger M, Davey Smith G, Schneider M, Minder C. Bias in meta-analysis detected by a simple, graphical test. BMJ. 1997;315(7109):629-634.

41. Hsu YH, Yang YT, Chen PN, et al. Association between pioglitazone and bladder cancer among patients with type II diabetes: a propensity score matched cohort study. Value in Health. 2014;17(3):A73.

42. Piccinni C, Motola D, Marchesini G, Poluzzi E. Assessing the association of pioglitazone use and bladder cancer through drug adverse event reporting. Diabetes Care. 2011;34(6):1369-1371.

43. Lin HC, Hsu YT, Kachingwe BH, et al. Dose effect of thiazolidinedione on cancer risk in type 2 diabetes mellitus patients: a six-year populationbased cohort study. J Clin Pharm Ther. 2014;39(4):354-360.

44. Kao CH, Sun LM, Chen PC, et al. A population-based cohort study in Taiwan--use of insulin sensitizers can decrease cancer risk in diabetic patients? Ann Oncol. 2013;24(2):523-530.

45. Mamtani R, Haynes K, Bilker WB, et al. Association between longer therapy with thiazolidinediones and risk of bladder cancer: a cohort study. J Natl Cancer Inst. 2012;104(18):1411-1421.

46. Bazelier MT, de Vries F, Vestergaard P, Leufkens HG, De Bruin ML. Use of thiazolidinediones and risk of bladder cancer: disease or drugs? Curr Drug Saf. 2013;8(5):364-370.

47. Kernan WN, Viscoli CM, Furie KL, et al. Pioglitazone after ischemic stroke or transient ischemic attack. N Engl J Med. 2016;374(14): 1321-1331.
48. Ching J, Amiridis S, Stylli SS, et al. The peroxisome proliferator activated receptor gamma agonist pioglitazone increases functional expression of the glutamate transporter excitatory amino acid transporter 2 (EAAT2) in human glioblastoma cells. Oncotarget. 2015;6(25): 21301-21314.

49. Wang Y, Tan H, Xu D, et al. The combinatory effects of PPAR-gamma agonist and survivin inhibition on the cancer stem-like phenotype and cell proliferation in bladder cancer cells. Int J Mol Med. 2014;34(1): 262-268.

50. Langle Y, Lodillinsky C, Belgorosky D, Sandes EO, Eijan AM. Role of peroxisome proliferator activated receptor-gamma in bacillus CalmetteGuerin bladder cancer therapy. J Urol. 2012;188(6):2384-2390.

51. Varley CL, Southgate J. Effects of PPAR agonists on proliferation and differentiation in human urothelium. Exp Toxicol Pathol. 2008;60(6):435-441.

52. Yang DR, Lin SJ, Ding XF, et al. Higher expression of peroxisome proliferator-activated receptor gamma or its activation by agonist thiazolidinedione-rosiglitazone promotes bladder cancer cell migration and invasion. Urology. 2013;81(5):1109.e1-6.

53. Lewis JD, Habel L, Quesenberry C, et al. Proteinuria testing among patients with diabetes mellitus is associated with bladder cancer diagnosis: potential for unmeasured confounding in studies of pioglitazone and bladder cancer. Pharmacoepidemiol Drug Saf. 2014;23(6): 636-645. 


\section{Supplementary materials}

Table SI Detailed reasons of excluded studies

\begin{tabular}{|c|c|}
\hline Study & Reason \\
\hline Balaji et al, ${ }^{12} 2014$ & Low NOS quality score \\
\hline Gupta et $a l,{ }^{13} 2015$ & Low NOS quality score \\
\hline Fujimoto et al, ${ }^{15} 2013$ & Low NOS quality score \\
\hline Hsu et al, ${ }^{22} 2014$ & Low NOS quality score \\
\hline Piccinini et al, ${ }^{23} 20 \mathrm{Il}$ & Low NOS quality score \\
\hline Lin et $\mathrm{al}^{24} 2014$ & Outcomes were not bladder cancer \\
\hline Kao et $a l,{ }^{25} 2013$ & Outcomes were not bladder cancer \\
\hline Lee et al," 2014 & $\begin{array}{l}\text { Bladder cancer case cohort }(n=84) \text { from } 2005 \text { to } 2009 \text { in NHI was overlapped by Hsiao }(n=3412) \text { in NHI from I997.I.I to } \\
2008.12 .31\end{array}$ \\
\hline Tseng et al, ${ }^{16} 2012$ & $\begin{array}{l}\text { Bladder cancer case cohort }(n=165) \text { from } 2006 \text { to } 2009 \text { in } \mathrm{NHI} \text { was overlapped by Hsiao }(n=34 \mid 2) \text { in NHI from I997.1.I to } \\
\text { 2008.12.3I }\end{array}$ \\
\hline Mamtani et al, ${ }^{26} 2012$ & Use rosiglitazone as referred group \\
\hline Bazelier et al, ${ }^{27} 2013$ & Use non-DM people as referred group \\
\hline Kernan et al, ${ }^{28} 2016$ & Use non-DM people as referred group \\
\hline Mackenzie et al, ${ }^{6} 2016$ & Without referred group \\
\hline Tuccori et al, ${ }^{17} 2016$ & Bladder cancer incident rate in exposed group is $5.8 \%$ which is abnormally higher than other cohort studies \\
\hline
\end{tabular}

Abbreviations: DM, diabetes mellitus; NHI, National Health Insurance; NOS, Newcastle-Ottawa scale.

Table S2 Characters of included RCT studies

\begin{tabular}{|c|c|c|c|c|c|c|c|c|c|}
\hline \multirow[t]{2}{*}{ Study } & \multirow[t]{2}{*}{ Age } & \multirow{2}{*}{$\begin{array}{l}\text { Sex } \\
\text { (percentage } \\
\text { of male) }\end{array}$} & \multirow[t]{2}{*}{ Study population } & \multirow{2}{*}{$\begin{array}{l}\text { Follow-up } \\
\text { (year) }\end{array}$} & \multirow[t]{2}{*}{ Intervention } & \multicolumn{2}{|c|}{ Intervention group } & \multicolumn{2}{|c|}{ Control group } \\
\hline & & & & & & Events & No events & Events & $\overline{\text { No events }}$ \\
\hline $\begin{array}{l}\text { Erdmann } \\
\text { et al, }{ }^{20} 2016, \\
\text { USA }\end{array}$ & 62 & 66 & $\begin{array}{l}\text { T2DM patients between } \\
\text { May 200I and April } \\
2002 \text { from primary-care } \\
\text { practices and diabetic or } \\
\text { cardiovascular specialist } \\
\text { departments in hospitals }\end{array}$ & 10.7 & $\begin{array}{l}\text { Pioglitazone } \\
\text { versus placebo }\end{array}$ & 27 & 2578 & 26 & 2607 \\
\hline $\begin{array}{l}\text { Vaccaro } \\
\text { et al, }{ }^{21} 2017, \\
\text { Italy }\end{array}$ & 62.3 & 59 & $\begin{array}{l}\text { T2DM patients of at least } \\
2 \text { years' duration and were } \\
\text { on stable treatment with } \\
\text { full-dose metformin }\end{array}$ & 4.8 & $\begin{array}{l}\text { Metformin plus } \\
\text { pioglitazone group } \\
\text { vs metformin plus } \\
\text { sulfonylureas group }\end{array}$ & 8 & 1527 & 8 & 1485 \\
\hline
\end{tabular}

Abbreviations: T2DM, type 2 diabetes mellitus; RCT, randomized controlled trial.

Random sequence generation (selection bias)

Allocation concealment (selection bias)

Binding of participants and personnel (performance bias)

Binding of outcome assessment (detection bias)

Incomplete outcome data (attrition bias)

Selective reporting (reporting bias)

Other bias
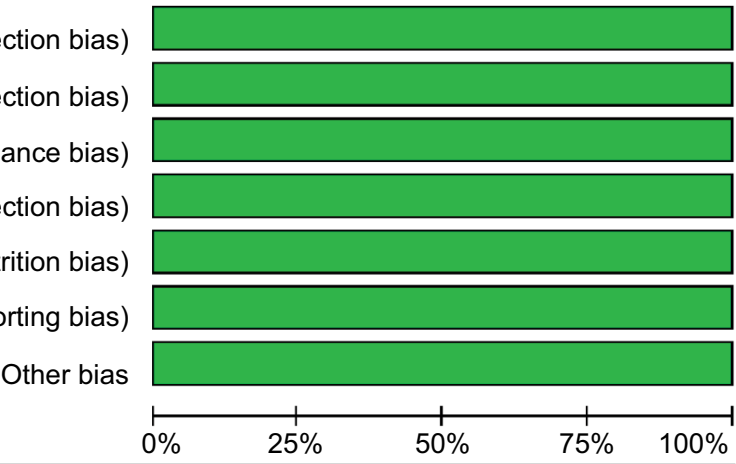

Low risk of bias $\square$ Unclear risk of bias $\quad \square$ High risk of bias

Figure SI Risk of bias assessment of two RCT studies.

Abbreviation: RCT, randomized controlled trial. 
Table S3 Sensitivity analysis of relative risks for the association between pioglitazone and bladder cancer

\begin{tabular}{|c|c|c|c|c|}
\hline \multirow[t]{2}{*}{ Study omitted } & \multirow[t]{2}{*}{$\operatorname{RR}(95 \% \mathrm{Cl})$} & \multicolumn{3}{|c|}{ Heterogeneity test } \\
\hline & & $\mathbf{Q}$ & $\mathbf{P}$ & $12(\%)$ \\
\hline Azoulay et al, ${ }^{8} 2012$ & $1.11(1.02-1.21)$ & 13.33 & 0.206 & 25 \\
\hline Neumann et al, ${ }^{5} 2012$ & $1.12(1.01-1.25)$ & 14.09 & 0.169 & 29 \\
\hline Hsiao et $\mathrm{al}^{4}{ }^{4} 2012$ & $1.13(1.02-1.24)$ & 15.64 & 0.11 & 36.1 \\
\hline Wei et al, ${ }^{9} 2013$ & $1.14(1.03-1.27)$ & 17.38 & 0.066 & 42.5 \\
\hline Vallarino et al, 72013 & $1.16(1.04-1.29)$ & 17.33 & 0.067 & 42.3 \\
\hline Kuo et al, ${ }^{2} 2014$ & $1.14(1.03-1.27)$ & 17.73 & 0.06 & 43.6 \\
\hline Lewis, et al, ${ }^{3} 2015$ & $1.14(1.02-1.28)$ & 16.98 & 0.075 & 41.1 \\
\hline Jin et al,' 2014 & $1.15(1.03-1.28)$ & 17.7 & 0.06 & 43.5 \\
\hline Korhonen et al, ${ }^{10} 2016$ & $1.16(1.04-1.30)$ & 17.65 & 0.061 & 43.3 \\
\hline Levin et al, ${ }^{14} 2015$ & $1.20(1.09-1.31)$ & 8.39 & 0.591 & 0 \\
\hline Han et al, ${ }^{18} 2016$ & 1.15 (1.03-1.27) & 17.82 & 0.058 & 43.9 \\
\hline Garry et al, ${ }^{19} 2018$ & $1.12(1.01-1.24)$ & 14.78 & 0.14 & 32.4 \\
\hline
\end{tabular}

\section{References}

1. Jin SM, Song SO, Jung CH, et al. Risk of bladder cancer among patients with diabetes treated with a $15 \mathrm{mg}$ pioglitazone dose in Korea: a multicenter retrospective cohort study. J Korean Med Sci. 2014;29(2):238-242.

2. Kuo HW, Tiao MM, Ho SC, Yang CY. Pioglitazone use and the risk of bladder cancer. Kaohsiung J Med Sci. 2014;30(2):94-97.

3. Lewis JD, Habel LA, Quesenberry CP, et al. Pioglitazone use and risk of bladder cancer and other common cancers in persons with diabetes. JAMA. 2015;314(3):265-277.

4. Hsiao FY, Hsieh PH, Huang WF, Tsai YW, Gau CS. Risk of bladder cancer in diabetic patients treated with rosiglitazone or pioglitazone: a nested case-control study. Drug Saf. 2013;36(8):643-649.

5. Neumann A, Weill A, Ricordeau P, et al. Pioglitazone and risk of bladder cancer among diabetic patients in France: a population-based cohort study. Diabetologia. 2012;55(7):1953-1962.

6. Mackenzie TA, Zaha R, Smith J, Karagas MR, Morden NE. Diabetes pharmacotherapies and bladder cancer: a medicare epidemiologic study. Diabetes Ther. 2016;7(1):61-73.

7. Vallarino C, Perez A, Fusco G, et al. Comparing pioglitazone to insulin with respect to cancer, cardiovascular and bone fracture endpoints, using propensity score weights. Clin Drug Investig. 2013;33(9):621-631.

8. Azoulay L, Yin H, Filion KB, et al. The use of pioglitazone and the risk of bladder cancer in people with type 2 diabetes: nested case-control study. BMJ. 2012;344:e3645.

9. Wei L, MacDonald TM, Mackenzie IS. Pioglitazone and bladder cancer: a propensity score matched cohort study. Br J Clin Pharmacol. 2013;75(1):254-259.

10. Korhonen P, Heintjes EM, Williams R, et al. Pioglitazone use and risk of bladder cancer in patients with type 2 diabetes: retrospective cohort study using datasets from four European countries. BMJ. 2016;354:i3903.

11. Lee MY, Hsiao PJ, Yang YH, Lin KD, Shin SJ. The association of pioglitazone and urinary tract disease in type 2 diabetic Taiwanese: bladder cancer and chronic kidney disease. PloS One. 2014;9(1):e85479.

12. Balaji V, Seshiah V, Ashtalakshmi G, Ramanan SG, Janarthinakani M. A retrospective study on finding correlation of pioglitazone and incidences of bladder cancer in the Indian population. Indian J Endocrinol Metab. 2014;18(3):425-427.

13. Gupta S, Gupta K, Ravi R, et al. Pioglitazone and the risk of bladder cancer: an Indian retrospective cohort study. Indian J Endocrinol Metab. 2015;19(5):639-643

14. Levin D, Bell S, Sund R, et al. Pioglitazone and bladder cancer risk: a multipopulation pooled, cumulative exposure analysis. Diabetologia. 2015;58(3):493-504.
15. Fujimoto K, Hamamoto Y, Honjo S, et al. Possible link of pioglitazone with bladder cancer in Japanese patients with type 2 diabetes. Diabetes Res Clin Pract. 2013;99(2):e21-23.

16. Tseng $\mathrm{CH}$. Pioglitazone and bladder cancer: a population-based study of Taiwanese. Diabetes Care. 2012;35(2):278-280.

17. Tuccori M, Filion KB, Yin H, et al. Pioglitazone use and risk of bladder cancer: population based cohort study. BMJ. 2016;352:i1541.

18. Han E, Jang SY, Kim G, et al. Rosiglitazone use and the risk of bladder cancer in patients with type 2 diabetes. Medicine (Baltimore). 2016;95(6):e2786.

19. Garry EM, Buse JB, Lund JL, Pate V, Sturmer T. Comparative safety of pioglitazone versus clinically meaningful treatment alternatives concerning the risk of bladder cancer in older US adults with type 2 diabetes. Diabetes Obes Metab. 2018;20(1):129-140.

20. Erdmann E, Harding S, Lam H, Perez A. Ten-year observational followup of PROactive: a randomized cardiovascular outcomes trial evaluating pioglitazone in type 2 diabetes. Diabetes Obes Metab. 2016;18(3): 266-273.

21. Vaccaro O, Masulli M, Nicolucci A, et al. Effects on the incidence of cardiovascular events of the addition of pioglitazone versus sulfonylureas in patients with type 2 diabetes inadequately controlled with metformin (TOSCA.IT): a randomised, multicentre trial. Lancet Diabetes Endocrinol. 2017;5(11):887-897.

22. Hsu YH, Yang YT, Chen PN, et al. Association between pioglitazone and bladder cancer among patients with type II diabetes: a propensity score matched cohort study. Value in Health. 2014;17(3):A73.

23. Piccinni C, Motola D, Marchesini G, Poluzzi E. Assessing the association of pioglitazone use and bladder cancer through drug adverse event reporting. Diabetes Care. 2011;34(6):1369-1371.

24. Lin HC, Hsu YT, Kachingwe BH, et al. Dose effect of thiazolidinedione on cancer risk in type 2 diabetes mellitus patients: a six-year populationbased cohort study. J Clin Pharm Ther. 2014;39(4):354-360.

25. Kao CH, Sun LM, Chen PC, et al. A population-based cohort study in Taiwan-use of insulin sensitizers can decrease cancer risk in diabetic patients? Ann Oncol. 2013;24(2):523-530.

26. Mamtani R, Haynes K, Bilker WB, et al. Association between longer therapy with thiazolidinediones and risk of bladder cancer: a cohort study. J Natl Cancer Inst. 2012;104(18):1411-1421.

27. Bazelier MT, de Vries F, Vestergaard P, Leufkens HG, De Bruin ML. Use of thiazolidinediones and risk of bladder cancer: disease or drugs? Curr Drug Saf. 2013;8(5):364-370.

28. Kernan WN, Viscoli CM, Furie KL, et al. Pioglitazone after ischemic stroke or transient ischemic attack. N Engl J Med. 2016;374(14) 1321-1331. 


\section{Publish your work in this journal}

Cancer Management and Research is an international, peer-reviewed open access journal focusing on cancer research and the optimal use of preventative and integrated treatment interventions to achieve improved outcomes, enhanced survival and quality of life for the cancer patient. The manuscript management system is completely online and includes a very quick and fair peer-review system, which is all easy to use. Visit http://www.dovepress.com/testimonials.php to read real quotes from published authors.

Submit your manuscript here: https://www.dovepress.com/cancer-management-and-research-journal 